\title{
Propriedades farmacológicas de Punica granatum $L$ (romã): uma revisão de literatura
}

\section{Pharmacological properties of Punica granatum L (pomegranate): a literature review}

\author{
Nágila Caroline Fialho Sousa ${ }^{1}$, Laoane Freitas Gonzaga ${ }^{2}$, \\ João Francisco Silva Rodrigues ${ }^{3}$, Elizabeth Soares Fernandes ${ }^{4}$
}

\begin{abstract}
RESUMO: A Punica granatum L. (Romã), família Punicaceae, é uma planta largamente utilizada na medicina popular para o tratamento de estomatites, faringites e laringites e é popularmente usada para rouquidão e inflamação da garganta. Sua utilização popular tem sido respaldada por estudos científicos de suas propriedades terapêuticas, principalmente antimicrobiana e anti-inflamatória. Estas propriedades têm sido estudadas em diferentes preparações desta planta, incluindo extratos e frações do fruto, flores e folhas; e parecem estar relacionadas ao alto teor de compostos fenólicos em suas composições. Este trabalho apresentará as diversas evidências das propriedades farmacológicas da $P$. granatum, compostos relacionados e aplicações atuais e futuras da utilização desta planta no tratamento de doenças de cunho inflamatório e/ou infeccioso.
\end{abstract}

PALAVRAS CHAVE: $P$. granatum; antimicrobiana; anti-inflamatória; antioxidante; compostos fenólicos.

\begin{abstract}
Punica granatum L. (Pomegranate), family Punicaceae, is a plant widely used in folk medicine for the treatment of stomatites, pharyngitis and laryngitis and is popularly used for hoarseness and inflammation of the throat. Its popular use has been supported by scientific studies of its therapeutic properties, mainly antimicrobial and anti-inflammatory. These properties have been studied in different preparations of this plant, including extracts and fractions of the fruit, flowers and leaves; and appear to be related to the high content of phenolic compounds in their compositions. This work will present the various evidences of the pharmacological properties of $P$. granatum, related compounds and current and future applications of this plant in the treatment of inflammatory and / or infectious diseases.
\end{abstract}

KEYWORDS: P. granatum; antimicrobial; anti-inflammatory; antioxidant; phenolic compounds.

\footnotetext{
${ }^{1}$ Acadêmica do $8^{\circ}$ período do curso de Farmácia da Universidade CEUMA - São Luís, aluna de iniciação científica PIBICFAPEMA. Membro atuante do grupo de pesquisa Imunofarmacologia e Neurofisiologia da Universidade Ceuma, tendo como linha de pesquisa a Avaliação de diferentes extratos com propriedades antioxidantes em modelos experimentais de inflamação. E-mail: nagila-caroline2011@live.com

${ }^{2}$ Acadêmica do $8^{\circ}$ período do curso de Farmácia da Universidade CEUMA - São Luís, aluna de iniciação científica voluntária. Membro atuante do grupo de pesquisa Imunofarmacologia e Neurofisiologia da Universidade Ceuma, tendo como linha de pesquisa o potencial antimicroniano de óleos essenciais sobre patógenos causadores de infecção sistêmica. E-mail: laoane_freitas@hotmail.com

${ }^{3}$ Graduado em Farmácia pela Universidade CEUMA, Mestre em Biologia Parasitária pelo Programa de Pós-graduação da Universidade CEUMA. Doutorando pelo Programa de Pós-graduação em Biodiversidade e Tecnologia-Rede BIONORTE. E-mail:joaofranciscosr@hotmail.com

${ }^{4}$ Professora Orientadora. Graduada em Ciências Biológicas pela Universidade do Vale do Rio Doce, Mestrado em Engenharia de Produção e Doutorado em Farmacologia pela Universidade Federal de Santa Catarina (UFSC). Pós-doutorado no exterior pelo CNPq (Kings College London, em Farmacologia). Atualmente é Professora do programa de Doutorado em Biotecnologia e Biodiversidade da Rede BIONORTE, Pós-graduação Mestrado em Biologia Parasitária e Odontologia ambos da Universidade do CEUMA. É Membro filiada da Academia Brasileira de Ciências. E-mail: elizabeth.soares@ceuma.br
} 


\section{Introdução}

Desde a Antiguidade, as plantas têm sido consideradas como fonte de alternativas terapêuticas, sendo utilizadas de forma empírica no tratamento de diferentes patologias (MORAES et al., 2010). São diversos os exemplos de produtos de origem botânica comercializados para o alívio de sinais e sintomas de patologias, além de diversas moléculas isoladas de plantas com potencial farmacológico (GASPARETTO, 2010). Exemplos importantes são o ácido acetilsalicílico e a vincristina, amplamente utilizados como anti-inflamatório e anti-câncer, respectivamente (BRANDÃO et al., 2010). O Brasil possui a mais rica flora de todo o mundo, composta por mais de 56.000 espécies de plantas identificadas (GULLIETTI et al., 2005; QUEIROZ, 2015), sendo, portanto, uma rica fonte de plantas com potencial farmacológico.

Dentre as diversas espécies botânicas com potencial terapêutico, destaca-se a Punica granatum conhecida popularmente como romã, planta da família Punicaceae. A romã não é nativa do Brasil, mas é cultivada aqui, especialmente no Maranhão; é um fruto que cresce em regiões de clima árido, é amplamente encontrada por todo Brasil sendo originária da Ásia (OLIVEIRA et al., 2010).

A produção do fruto se dá no período de setembro a fevereiro (MARTINS, 1995). É amplamente utilizada por muitos povos, sendo um fruto com uma longa história medicinal, principalmente entre os orientais. Nos últimos anos houve um renovado interesse mundial sobre os benefícios funcionais e nutracêuticos desse fruto (SUMNER et al., 2005). É um tipo de planta arbustiva que cresce entre 3 a 5 metros, as suas folhas são opostas e fasciculadas, brilhantes, alternadas e obtusas. As suas flores emergem agrupadas em florescências nas extremidades e possuem um cálice tubular e suculento. Os seus frutos são em de forma arredondada, com uma casca dura de cor amarelo avermelhado, quando maduros rebentam expondo as suas sementes (MYERS et al., 2000).

A romã é utilizada popularmente desde Antiguidade, de forma empírica. Atualmente, estudos científicos in vitro e in vivo com diferentes preparações desta planta têm respaldado suas propriedades antimicrobianas e anti-inflamatórias. (LEE et al., 2010, ISMAIL et al., 2012). Estas atividades têm demonstrado o potencial terapêutico de seu fruto, de partes como a casca, folhas e sementes.

Estima-se que $40 \%$ dos medicamentos disponíveis na terapêutica atual foram desenvolvidos a partir de fontes naturais, sendo que, dentre os fármacos aprovados no período entre 1981 e 2002, cerca de $60 \%$ eram produtos naturais ou foram desenvolvidos a partir destes 
(CALIXTO, 2003; NEWMAN \& CRAGG, 2007). Diante disso, perante as diversas alternativas para o tratamento de doenças, observa-se a necessidade de novas alternativas farmacológicas, e que sejam de fácil acesso à população carente.

Um estudo realizado pelo RENISUS- Relação Nacional de Plantas Medicinais, divulgada pelo Programa Nacional de Plantas Medicinais e Fitoterápicos do Ministério da Saúde teve como objetivos orientar a elaboração de uma relação de fitoterápicos disponíveis para o uso da população, com segurança e eficácia para o tratamento de doenças. Neste estudo, foram listadas várias espécies de plantas medicinais e dentre elas, encontra-se a romã (MINISTERIO DA SAÚDE, 2009, DEGÁSPARI et al., 2011). A seguir, as ações farmacológicas mais bem estudadas da romã serão discutidas, bem como serão apresentadas evidências dos potenciais compostos envolvidos nas propriedades terapêuticas de $P$. granatum.

\section{Atividades farmacológicas da romã}

\section{Atividade antimicrobiana}

As propriedades antimicrobianas de produtos derivados de plantas têm sido demonstradas contra diferentes patógenos. Em algumas bactérias, os dados da literatura relatam que os extratos de casca de Punica granatum em diferentes concentrações foram eficazes contra diferentes espécies bacterianas, como S. aureus, E. coli, Salmonella enterica, Shigella sonnei, Enterococcus faecalis e Bacillus subtilis (PAGLIARULO et al., 2016; E. C. ROSAS-BURGOS et al., 2017). A quantidade de polifenóis totais variou dependendo das partes da fruta, em particular sendo maior na casca do que nos extratos de suco (PAGLIARULO et al., 2016). Ainda, foi mostrado que o extrato da casca (romã) inibe o crescimento e a sobrevivência de ambas as cepas. Num estudo anterior, os compostos bioativos de $P$. granatum foram extraídos utilizando solventes aquosos, metanol, etanol, acetona, éter e clorofórmio. No entanto, em um estudo, as frações alcalinas solúveis em água contêm o maior número de ácidos fenólicos e são mais eficazes contra bactérias Gram-positivas (PRAJNA et al., 2013). MARTINSA et al., (2012) também revelou que a atividade antibacteriana das frações foi mais eficaz ao inibir o crescimento de bactérias Gram-positivas quando comparadas com bactérias Gram-negativas.

Em outro artigo publicado por KHAN et al., (2017) foram coletadas e isoladas frações pelo método de HPLC (aquoso, hexânico, etanol e clorofórmico), por outro lado, apenas a fração aquosa e hexânica demonstraram atividades antimicrobianas para tais bactérias na tabela abaixo: 


\begin{tabular}{ccc}
\hline Bactéria & Extrato Aquoso & Extrato Hexânico \\
\hline P. aeroginosa & Sim & Sim \\
S. aureus & Não & Sim \\
E. coli & Sim & Sim \\
\hline
\end{tabular}

Tabela 1. Resultado de HPLC de extrato aquoso e hexânico da P.granatum

Segundo CATÃO et al., (2006) compararam a eficiência de antimicrobianos usados rotineiramente na clínica médica aos resultados apresentados pelo extrato etanólico de romã a $10 \%$. Avaliaram 17 cepas de $S$. aureus de origem humana ambulatorial e registraram que o extrato de romã foi capaz de inibir 100\% das cepas analisadas, enquanto que 64,7\% apresentaram resistência à penicilina e à ampicilina.

A cerca dos compostos responsáveis pela ação antimicrobiana dessa planta, encontra-se a punicalagina, um tanino elágico derivado do fruto da romã, como um dos principais constituintes antimicrobianos da fruta (MOORTHY et al., 2013).

Tem sido sugerido também que essa planta contém componentes que podem beneficiar a saúde da boca. Li et al (2005) relataram o poder inibitório in vitro de um extrato da flor do $P$. granatum sobre uma enzima bacteriana digestiva da sucrose que é considerado o fator responsável por despertar problemas orais, como a gengivite. Em outros dois estudos, a lavagem bucal aguda com diferentes extratos removeu placas bacterianas dos dentes de voluntários (DI SILVESTRO, 2009).

\section{Atividade anti-inflamatória}

Experimentos demonstraram que os compostos fenólicos da romã representaram influência sobre a modulação de respostas antiinflamatórias (ARUN; SINGH, 2012). Porém, pouco se sabe dos compostos presentes em outras frações das folhas da romã com ação anti-inflamatória.

SANTOS et al., (2014) avaliando a atividade de Punica granatum contra Staphylococcus aureus isolados de mastite bovina e ação anti-inflamatória in vivo, constataram que o extrato da casca do fruto em todas as concentrações testadas inibiu todos os microrganismos isolados e também demonstrou redução do edema de pata nas concentrações testadas. Foi observado que houve a redução de efeito dose-resposta nos edemas por carragenina tratados por esse extrato. A redução do edema da pata está relacionada com a interrupção do mecanismo de síntese de prostaglandina. Sendo assim, é possível que possa ter influenciado na redução do edema assim como o fármaco de referência Indometacina (AINES). Dentre os mecanismos envolvidos no efeito 
anti-inflamatório da romã, estudos realizados demonstraram que a mesma é capaz de inibir a ativação de vias inflamatórias incluindo o NF-אB 3 . Entre os compostos com essa atividade podem ser citados, flavonóides, esteróis, triterpenos e ácidos orgânicos, que estão presentes no fruto.

\section{Atividade antioxidante}

Segundo NODA et al. (2002), que avaliaram extrato acetônico de romã, foi apontado que, para atividade antioxidante, há a contribuição de três antocianinas: delfinidina, cianidina e pelargonidine.

As enzimas do sistema de defesa antioxidante endógeno como a superóxido dismutase, catalase e glutationa peroxidase, resgistraram efeito antioxidante no suco da romã (AJAIKUMAR et al., 2005). Os flavonóides extraídos do suco fermentado e do óleo da romã tiveram atividade inibitória das enzimas oxidantes ciclooxigenase e lipooxigenase (SCHUBERT, LANSKI, NEEMAN, 1999). A romã é rica em compostos fenólicos que exibem forte atividade oxidante in vitro (SAXENA et al, 2004). São popularmente consumidos nas formas in natura, sucos, alimentos como doces e geléias e extratos, os quais são utilizados como ingredientes botânicos na medicina natural e suplementos alimentares (MOHAGHEGHI et al., 2011).

Portanto, foi demonstrado que o extrato hidroalcoólico extraído das cascas de $P$. granatum apresentou atividade antioxidante com valores correspondente à alta atividade antioxidante com IC50\% (MOREIRA et al., 2014). E em outro estudo anteriormente por MORAIS et al., (2013) avaliaram o extrato etanólico e relacionaram que sua atividade antioxidante é devido ao teor de fenóis totais encontrado na planta.

No estudo realizado por PANDE \& AKOH (2009), avaliou-se a capacidade antioxidante e o perfil lipídico. Os resultados mostraram que a casca teve o maior teor de taninos hidrolisáveis. Em geral, a capacidade antioxidante foi encontrada em folhas, seguidas de casca, polpa e sementes. As sementes obtiveram teor médio de lipídeos de 19,2\%. A casca é utilizada para tratar as infecções dos órgãos masculinos e femininos, acne, mastite, dermatite alérgica e alguns tratamentos de doenças orais (NASCIMENTO et al., 2015). E em outros trabalhos como o de (AL-MUAMMAR et al, 2012; BEKIR et al., 2013) que foram apresentados sobre o extrato das folhas da romã apresentaram capacidade de combater a obesidade. Porém, em outra pesquisa realizada por (RADHIKA et al., 2013) foi administrado o suco em ratos diabéticos e foi demonstrado que, nos exames histopatológicos, o extrato impediu alterações degenerativas induzidas por diabetes. E também no mesmo estudo mostrou-se uma ação anti-hipertensiva nesses animais. 
As cascas de romã são consideradas partes não comestíveis ou subproduto, obtido durante o processamento do suco. É caracterizado pela presença significativa de polifenóis como elagitaninos, ácido elágico e ácido gálico (FARIA, 2010) e de flavonóides, os quais estão associados a propriedades biológicas, como agente antioxidante e antimicrobiano (DOYMAZ, 2011) O estudo traz benefícios relacionados com a prevenção de processos oxidativos que começam com a participação de radicais livres (JURENKA, 2008).

De acordo com a equipe de DISILVESTRO et al., (2009) parece que o estresse oxidativo que prejudica as gengivas e potencializa a gengivite é eficazmente combatido pelos flavonóides da romã, que varrem os radicais livres e induzem enzimas antioxidantes endógenas. Os mesmos flavonóides também exercem efeito anti-inflamatório e antibacteriano in vitro contra cepas importantes no processo da gengivite, ambos os mecanismos são relevantes, uma vez que a inflamação é um aspecto básico de muitos problemas orais.

FUHRMAN \& AVIRAM, (2001) fizeram uma revisão a respeito do efeito antioxidante dos flavonoides. Os estudos comprovam que diferentes grupos de flavonóides e taninos presentes o suco de romã inibem a oxidação de LDL, in vitro e in vivo. Além de reduzir a capacidade de macrófagos oxidarem LDL, a administração do suco da fruta reduziu a e atenuou o desenvolvimento de lesões ateroscleróticas em ratos.

\section{Medicamentos ou fitoterápicos à base de $P$. granatum $L$ e suas aplicações}

Os medicamentos fitoterápicos são preparações vegetais padronizadas que consistem de uma mistura complexa de uma ou mais substâncias presentes na planta e precisam ser devidamente preparados e prescritos em obediência à legislação vigente. P. granatum é utilizada por uma formulação de fitoterápico pelo método de infusão, sendo considerada a proporção indicada na fórmula de $6 \mathrm{~g}$ de cascas da planta para $150 \mathrm{ml}$ de água q.s.p. É indicada como anti-inflamatório e antisséptico da cavidade oral, uso externo, fazendo-se bochechos ou gargarejos três vezes ao dia (Formulário de Fitoterápicos da Farmacopeia Brasileira, 2011).

Outra fórmula bastante utilizada é o óleo da romã, extraído das sementes, como fonte natural de ácido punícico e ácido elágico. E ajudam na regeneração e proliferação celular. É um poderoso hidratante, antioxidante e adstringente. Ainda, em cultivo popular usa-se o xarope do suco da romã, para o tratamento de garganta, o chá da casca também para a infecção de garganta, na forma de gargarejo. Até o momento, em algumas farmácias de manipulação é vendido o extrato seco da romã, com finalidade antioxidante, clareador da pele, elasticidade do cabelo, além de melhorar o perfil lipídico em pacientes diabéticos com hiperlipidemia, e outros fins terapêuticos. 
Portanto, usado de forma racional, pois em excesso poderá ocasionar intoxicação e relatos de morte (Acácia, Farmácia de Manipulação, SP-2018).

\section{Novas formulações e futuras aplicações}

\section{Formulação bucal contendo extrato de $P$. granatum para tratamento de estomatites (tablete ou gel)}

É indicada para o tratamento de candidíase associada com estomatite protética, cuja base é extraída da casca da planta, sendo o principio ativo isolado a punicalagina, através do método de microdiluição em caldo, que resultou na concentração capaz de inibir o crescimento fúngico e a candidíase, que é a infecção fúngica mais comum na boca. A prótese total pode induzir alterações inflamatórias na mucosa que a suporta, e tais alterações são denominadas estomatite protética, uma vez que a presença da prótese é o fator contribuinte preponderante. $\mathrm{O}$ tratamento consiste em associar um antifúngico tópico com orientações ao paciente quanto à necessidade de correção de prótese, remoção da prótese à noite e uma higienização adequada. Tais candidíases associadas à estomatite protética não são de fácil tratamento e podem ocorrer recidivas e, assim, representam um desafio à prática estomatológica, face a sua frequência e o pequeno número de drogas antifúngicas disponíveis. Devido à toxicidade e custo elevado de antifúngicos sintéticos, faz-se necessária a pesquisa por novos agentes antifúngicos e as plantas são uma fonte de substâncias bioativas que vêm ganhando interesse científico. A busca de novas substâncias oriundas de plantas visa moléculas com alta seletividade, baixa toxicidade e alto potencial farmacológico. Assim, o objetivo da presente patente é a apresentação de formulação tópica para o tratamento de micoses bucais, tendo em vista sua alta incidência, incorporando na forma de gel ou tablete o extrato derivado da espécie vegetal $P$. granatum ou nanopartículas e/ou micropartículas contendo o extrato ( NAKAMURA et al., 2012).

BACCARIN et al., (2015) descrevem o desenvolvimento de nanoemulsões do tipo óleo em água contendo constituintes de Punica granatum e hidrogéis termossensíveis incluindo nanoemulsões para aplicação cutânea, visando sua utilização na fotoproteção. A fração acetato de etila foi obtida através da partição líquidolíquido, a partir do extrato seco das cascas de $P$. granatum, e foi caracterizado pela quantificação de polifenóis totais, ácido gálico, ácido elágico e punicalagina. Concluíram que a nanoemulsão contendo óleo de semente de romã e fração acetato de etila encapsulada desenvolvida, como também o hidrogel termosensível, constituem uma boa estratégia para facilitar a aplicação cutânea, aprimorar a retenção e permeação de compostos fenólicos nas camadas da pele e favorecer a ação fotoprotetora. 


\section{Métodos utilizados}

O presente estudo é uma breve revisão sobre as propriedades farmacológicas da romã em artigos publicados em Inglês e Português. Para as buscas de artigos científicos sobre este tema foram feitas buscas de dados do Pubmed, SciELO, Science Direct, e LILACS. Para a busca dos artigos foram utilizadas palavraschaves como: P. granatum, atividades antimicrobianas, anti-inflamatórias, antioxidante.

\section{Conclusão}

Considerando os dados levantados nesse estudo, constatou-se que as atividades antimicrobiana, anti-inflamatória e antioxidante da romã são comprovadas cientificamente em estudos in vivo e in vitro. Assim, como a parte da planta, e o solvente utilizado para a preparação do extrato, pois os solventes vão extrair os compostos polares ou apolares, que nos experimentos cada extrato pode expressar uma função metabólica diferente. Diante os efeitos relatos da romã, surge o interesse da comunidade científica em buscar novas terapêuticas eficazes no combate de enfermidades. E que desperta-se o interesse da população em aumentar o consumo por produtos naturais, que não possam trazer efeitos danosos ao organismo.

\section{Referências Bibliográficas}

ACÁCIA DE AMERICANA FARMÁCIA E MANIPULAÇÃO. Americana-SP. 2018

AJAIKUMAR, K. B.; ASHEEF, M. BABU, B.H, PADDIKALA, J. The innibition of gastric mucosal injury by punica granatum 1, (pomegranate) methanolic extract. J. Ethnopharmacol., V. 96, 171-176, 2005.

AL-MUAMMAR, M.N., FOZIA. KHAN, F. 2012. Obesity: the preventive role of the pomegranate (Punica granatum). Nutrition 29, 595-604.

ARUN, N.; SINGH, D.P. Punica granatu: A review on pharmacological and therapeutic properties. International Journal of Pharmaceutical Sciences and Research. V.3. p.1240-1245, 2012.

BACCARIN, THAISA (2015). Desenvolvimento de Nanoemulsões contendo constituintes de Punica granatum para aplicação cutânea visando sua utilização na fotoproteção. Dissertação (mestrado)-UFSC, Ciências da Saúde. Florianópolis, 2015.

BEKIR et al. Assessment of antioxidant, anti-inflammatory, anti-cholinesterase and citotoxy activies of pomegranate (Punica granatum) leaves, Food and Chemical Toxicology 55 (2013). 470475 . 
BRANDÃO HN, DAVID JP, COUTO RC, NASCIMENTO JAP, DAVID JM, 2010. Química e farmacologia de quimioterápicos antineoplásicos derivados de plantas. Química Nova, 33, 13591369.

BRASIL. AGÊNCIA NACIONAL DE VIGILÂNCIA SANITÁRIA. FORMULÁRIO DE FITOTERÁPICOS DA FARMACOPÉIA BRASILEIRA. Agência Nacional de Vigilância Sanitária. Brasília: Anvisa, 2011. 126p.

CALIXTO, J.B. Biodiversidade como fonte de medicamentos. Ciência e Cultura, v.55, p.37-39, 2003.

CATÃO R.M.R., ANTUNES R.M.P., ARRUDA T.A., PEREIRA M.S.V., HIGINO J.S., ALVES J.A., PASSOS M.G.V.M. \& SANTOS V.L. 2006. Atividade antimicrobiana. Revta Bras. Anal. Clin. 38:111-114.

DEGÁSPARI et al. Phytotherapy properties from promagranate (punica granatum 1.), Visão acadêmica, Curitiba, v. 12, n.1. Jan.-Jun. 2011- ISSN 1518-5192.

DISILVESTRO, R. A.. et al. Pomegranate Extract Mouth Rinsing Effects on Saliva Measures Relevant to Gingivitis Risk. Phytother Res, 23: 1123- 1127, 2009.

DOYMAZ, I. Experimental Study on Drying Characteristics of Pomegranate Peels. Food Sci. Biotechnol. 2011, 20(4), 965-970.

FARIA, A.; CALHAU, C. Pomegranate in human health: An overview. Bioactive Foods in Promoting Health: Fruits andVegetables. Watson RR, Preedy VR (eds). Academic Press, Amsterdam, Netherlands . 2010, 551-563.

GASPARETTO, J.C., CAMPOS, F.R., BUDEL, J.M., PONTAROLO, R.Estudos agronômicos, genéticos, morfoanatômicos, químicos, farmacológicos, toxicológicos e uso nos programas de fitoterapia do Brasil. Revista. Brasileira. Farmacognosia. 20, 627- 640. 2010.

GIULIETTI, A. M.; HARLEY, R. M.; de QUEIROZ, L. P.. WANDERLEY, M.G.L.; VAN DEN BERG, C. Biodversidade e conservação das plantas do Brasil. Mega diversidade 1 (1):52-61.2005.

ISMAIL T., SESTILI P. \& AKHTAR S. 2012. Pomegranate peel and fruit extracts: A review of potential anti-inflammatory and anti-infective effects. J. Ethnopharmacol. 143:397-405.

JURENKA, J. Therapeutic applications of pomegranate (Punica granatum L.): a review. Altern. Med. Rev., V 13, n.2, p. 128-144, 2008.

KHAN I, RAHMAN H, ABD EL-SALAM NM, TAWAB A, HUSSAIN A, KHAN TA, KHAN UA, QASIM M, ADNAN M, AZIZULLAH A, MURAD W, JALAL A, MUHAMMAD N, ULLAH R. Punica granatum peel extracts: HPLC fractionation and LC MS analysis to quest compounds having activity against multidrug resistant bacteria.2017 May 3;17(1):247. doi: 10.1186/s12906-017-1766-4. 
LANSKY \& NEWMAN, D.J.; CRAGG, G.M. Natural Products as Sources of New Drugs over the Last 25 Years. Journal of Natural Products, v.70, p.461-477, 2007.

LEE C.J., CHEN L.G., LIANG W.L. \& WANGA C.C. 2010. Anti-inflammatory effects of Punica granatum Linne in vitro and in vivo. Food Chemistry 118:315-322.

LI, Y. F. et al. Evaluation of antioxidant properties of pomegranate peel extract in comparison with pomegranate pulp extract. Food Chemistry, v. 96, n. 2, p. 254-260, May 2006. ISSN 0308-8146. MARTINS, E. Plantas medicinais. Viçosa: UFV, p.162-163, 1995.

MARTINSA S, ELBA ALC, SOBRINHOB TJSP, SARAIVAC AM, PISCIOTTANOC MNC, AGUILARD CN, TEIXEIRAA JA, MUSSATTOA SI. Antibacterial activity of crude methanolic extract and fractions obtained from Larrea tridentata leaves. Ind Crops Prod. 2012; 41:306-11.

MENEZES S.M.S., PINTO D.M. \& CORDEIRO L.N. 2008. Atividades biológicas in vitro e in vivo de Punica granatum L. (romã). Revta Bras. Med. 65:388-391.

MINISTÉRIO DA SAÚDE. Programa Nacional de Plantas Medicinais e Fitoterápicos, Brasília, 2007.(disponívelemhttp://portal.saude.gov.br/portal/arquivos/pdf/politica_plantas_medicinais_fitote rapia.pdf).

MOHAGHEGHI, M.; REZAEI, K; LABBAFI, M.; Mousavi, S. M. E. Pomegranate seed oil as a functional ingredient in beverages. European Journal of Lipid Science and Technology, 2011, $113,730-736$.

MOORTHY K., PUNITHA T., VINODHINI R., THIPPAN B., SURESHKUMAR B.T. \& VIJAYALAKSHMI P. 2013. Antimicrobial activity and qualitative phytochemical analysis of Punica granatum Linn. (PERICARP). J. Med. Plants Res. 7:474-479.

MORAES, J. Q.; NUNES, J. R. S.; PINHEIRO, A. P.; PESSOA, S. P. M. Etnobotânica de plantas medicinais com alunos do ensino médio de um colégio estadual de Tangará da Serra-MT. $3^{a}$ jornada científica da Unemat, Cáceres/MT Brasil, 20-24 setembro, 2010.

MORAIS S.M., LIMA K.S.B., SIQUEIRA S.M.C., CAVALCANTI E.S.B., SOUZA M.S.T., MENEZES J.E.S.A. \& TREVISAN M.T.S. 2013. Correlação entre as atividades antiradical, antiacetilcolinesterase e teor de fenóis totais de extratos de plantas medicinais de farmácias vivas. Revta Bras. Plantas Medicinais 15:575-582.

MOREIRA, G.M.B., MATSUMOTO, L.S., SILVA, R.M.G.,. DOMINGUES, P.F., PEIXOTO, E C.T. M. Atividade antibacteriana do extrato hidroalcoólico de Punica granatum Linn. sobre Staphylococcus spp. isolados de leite bovino. Pesq. Vet. Bras. 34(7):626-632, julho 2014. 
MYERS, N. et al. Biodiversity hotspots for conservation priorities. Nature, v. 403, n. 6772, p. 853$857,2000$.

NAKAMURA, T.U.; CORTEZ, D.A.G.; FILHO, B.P.D.; NAKAMURA, V.C.; ENDO, E.H.; FORMULAÇÃO BUCAL CONTENDO EXTRATO DE Punica granatum PARA TRATAMENTO DE ESTOMATITES. Patente, 2012.

NASCIMENTO, J. B. Use of medicinal plants in the treatment of recurrent apthous stomatitis in the city of Petrolina-Pernambuco, Brazil, v., n.3, setldez. 2015. UnirG, Gurupi, TO, Brasil.

Noda Y., Kaneyuki T., Mori A. \& Packer L. 2002. Antioxidant activities of pomegranate fruit extract and its anthocyanidins: delphinidin, cyanidin, and pelargonidin. J. Agricult. Food Chem. 50:166-171.

OLIVEIRA, L.P. et al. Atividade citotóxica e antiangiogênica de Punica granatum L., Punicaceae. Revista brasileira de farmacognosia, v.20, n.2, p.201-207, abrımaio, 2010.

PAGLIARULO, V. DE VITO, G. PICARIELLO et al., "Inhibitory effect of pomegranate (Punica granatum L.) polyphenol extracts on the bacterial growth and survival of clinical isolates of pathogenic Staphylococcus aureus and Escherichia coli," Food Chemistry, vol. 190, pp. 824-831, 2016.

PANDE, G, \& AKOH, C.C.2010. Antioxidant Activity of Punica granatum.

PRAJNA J, RICHA J, DIPJYOTI C. HPLC Quantification of Phenolic Acids from Vetiveria zizanioides (L.) Nash and Its Antioxidant and Antimicrobial Activity. J Pharm. 2013;6:1-6.

RADHIKA et al., a review on ethnic florae with antihyperglycemic efficacy, International Journal of Herbal Medicine 2013; 1 (4): 55-62.

RICCI et al, Antioxidant activity of Punica granatum fruits, Fitoterapia 77 (2006) 310-312.

ROSAS-BURGOS, A. BURGOS-HERNÁNDEZ, L. NOGUERA-ARTIAGA et al., "Antimicrobial activity of pomegranate peel extracts as affected by cultivar," Journal of the Science of Food and Agriculture. vol. 97, no. 3, pp. 802-810, 2017.

SANTOS, L.A.; MENEZES, J.S.; RUFINO, L. R. A. OLIVEIRA, N. M.S. FIORINI, J.E. 2014. Avaliação da atividade de P. granatum contra Staphylococcus aureus Isolados de Mastite Bovina e Ação Anti-inflamatória “in vivo". doi: http://dx.doi.org/10.5892/ruvrd.v12i1.1557

SAXENA, A.; VIKRAM, N. K. Role of selected Indian plants in management of type 2 diabetes: A review. Journal of Alternative and Complementary Medicine, 2004,10, 369-378.

SUMNER, M. D., ELliOTT-ELlER, M., WEIDNER, G., DAUBENMIER, J. J., CHEW, M. H., MARLIN, R.. Effects of pomegranate juice consumption on myocardial perfusion in patients with coronary heart disease. Journal of Cardiology, 96, 810-814, 2005. 